\title{
LA INDUSTRIA DE LOS MEDICAMENTOS, EL NEGOCIO QUE LUCRA CON LA ENFERMEDAD
}

The Drug industry, business that profits with disease

\author{
Marco Antonio Ramírez Campos ${ }^{1, a, b}$ \\ ${ }^{1}$ Universidad Nacional San Cristóbal de Huamanga. Ayacucho, Perú. \\ ${ }^{a}$ Bachiller en Ciencias Agrícolas \\ ${ }^{\mathrm{b}}$ Especialista en Sanidad Vegetal
}

\section{RESUMEN}

El uso de medicamentos surge a partir de la necesidad de la población por el tratamiento de enfermedades que antes eran imposibles de curar y que en primera instancia surge por medio de la extracción de sustancias de diversas plantas utilizadas en la medicina tradicional. Posteriormente la obtención artificial de componentes bioquímicos utilizados para la cura de enfermedades, causó un gran impacto en la medicina, iniciando así, la fabricación y uso masivo de medicamentos con el continuo desarrollo de la industria farmacéutica. Este hecho le ha permitido una enorme responsabilidad sobre la protección, mejoramiento y curación de enfermedades como el cáncer, diabetes, problemas cardiacos entre otros, sin embargo, los medicamentos también pueden causar problemas tan grandes que pondrían en riesgo la salud de millones de personas en todo el mundo, principalmente a través de programas sanitarios que incluyen grupos humanos grandes y vulnerables como los niños, ancianos, mujeres gestantes, etc.

La industria farmacéutica está regido por grandes empresas provenientes de países desarrollados cuya influencia dentro del mercado mundial le permiten ventas por unos 170000 millones de dólares en el mundo y un crecimiento constante. Hoy en día, la actividad económica en materia de salud es uno de los sectores empresariales más rentables e influyentes en el mundo, constituido básicamente por una competencia oligopólica a través de la dependencia productos y una gran deficiencia en la investigación.

Palabras Clave: Industria, medicamentos, negocio, enfermedad

\section{SUMMARY}

The use of drugs arises from the need of the population for the treatment of diseases that were previously impossible to cure and arises in the first instance by extracting substances from various plants used in traditional medicine. Then the artificial production of biochemical components used for the cure of diseases, caused a great impact in medicine, starting well, manufacture and widespread use of drugs with the continuing development of the pharmaceutical industry. This has allowed a huge responsibility for the protection, improvement and cure of diseases such as cancer, diabetes, heart problems and others, however, medications can also cause such big problems that might endanger the health of millions of people in worldwide, primarily through health programs including large human and vulnerable groups such as children, the elderly, pregnant women, etc..

The pharmaceutical industry is governed by large companies from developed countries whose influence in the global market allow sales of about 170000 million dollars worldwide and a steady growth. Today, economic activity in health is one of the most profitable and influential business sectors in the world, consisting basically of an oligopolistic competition through reliance products and a deficiency in the investigation.

Keywords: Industry, medicine, business, disease 


\section{INTRODUCCION.}

La salud es uno de los bienes más preciados por la humanidad y en su concepto más universal expresa el estado completo de bienestar físico y mental. El cuestionamiento acerca de cómo solucionar el gran problema de las enfermedades que causan la muerte de millones de personas en todo el mundo, nos lleva a reflexionar sobre la gran importancia de una medicina alternativa $y$ responsable basadas en un sistema de prevención frente a un acelerado incremento de pacientes en el mundo. Sin embargo, estos conceptos están siendo de lado en una sociedad dependiente y con un entendimiento sobre la salud de manera errada puesto que la salud es un estado que se consigue a través de ciertos factores indispensables como la actividad física y una alimentación basada en el consumo de productos no dañinos mediante la promoción del tema a partir de una educación básica impartida en los centros escolares.

\section{LA FILOSOFIA DE LOS MEDICAMENTOS.}

Actualmente se considera que más del $70 \%$ de enfermedades en todo el mundo es ocasionado por estrés, donde la salud mental es una cuestión que viene incrementándose de manera alarmante. Este hecho ha generado un aumento de pacientes con una necesidad por tener un tratamiento eficaz que sumado a un estilo de vida con alimentación no adecuada y poco entrenamiento físico ha conllevado al uso masivo de medicamentos en una sociedad donde la práctica de prevención de una enfermedad es casi nula. Sin embargo debemos preguntarnos ¿cuán necesario puede ser el uso de medicamentos?, ¿Cuál es el momento adecuado para recurrir a un tratamiento farmacológico?, ¿Por qué siempre dependemos de ellos? Sin duda, es importante el rol que cumplen los fármacos sobre enfermedades que generan un riesgo en la salud, especialmente cuando hablamos sobre enfermedades infectocontagiosas o aquellas que afectan a gran parte de la población pero no podemos negar que la mayor parte de estas alteraciones supuestamente físicas tienen más bien un origen psicológico y que la solución está en preocuparnos más por la salud física sin dejar de lado la mental bajo un concepto de prevención.

Se sabe que de manera natural el cuerpo humano tiene la propiedad de auto sanación que le permite reponerse de ciertas afecciones, sin embargo, ante las grandes campañas publicitarias donde se vende un medicamento como la solución a un problema, dicho paciente empieza a ser más dependiente de algo que antes no lo era. Es claro que el poder que tiene esta industria para vender sus productos a través de la publicidad en gran medida contribuye al consumo innecesario de medicamentos que no tienen nada que ver con una enfermedad real (1). Este hecho ha permitido en gran medida el uso de medicamentos sin ningún valor de los llamados placebos, que aparentemente pueden tener grandes efectos en la salud de una persona sin realmente tenerlo.

\section{EL ENGAÑO DETRÁS DE LA PUBLICIDAD.}

Muchas veces hemos observado en la televisión la enorme variedad de productos ofrecidos como la cura o la solución a muchos problemas de salud que aquejan a la población. La venta de medicamentos probablemente sea uno de los negocios más rentables en el mundo puesto que vender algo a costa de una necesidad indispensable como la salud, ofrece ingresos multimillonarios para las empresas dedicadas a este rubro.

Según las reglas del libre mercado donde una empresa puede vender un producto al precio que le conviene y utilizar la información que le conviene para vender mejor su producto, no siempre permite tener una idea clara de lo que se estamos comprando. Un caso claro es la venta de leche para el primer año de vida donde se menciona que este producto es lo mejor para un niño a esta edad. No cabe 
duda que la manipulación de conceptos sobre la salud es evidente, ya que se sabe que la mejor leche para un bebe es el de la madre. Otro caso es el de los suplementos nutricionales que supuestamente permiten un mejor desempeño en la actividad diaria sin sufrir cansancio o agotamiento. Esto puede hacer pensar que dicho producto puede ser consumido con cierta libertad o sin receta médica, pero ¿Qué sucede realmente con estos suplementos? Según investigaciones recientes se sabe que estos productos desarrollan cáncer de colon principalmente en adolescentes y adultos. El consumo de suplementos solo está destinado para aquellas personas con una necesidad nutricional importante como los niños, madres gestantes, adultos mayores entre otros.

Lamentablemente esta industria gasta fortunas no sólo en publicidad sino que garantiza su alta rentabilidad gracias a su estrategia para adquirir voluntades a través de costosas conferencias o capacitaciones para el gremio médico, en forma de agasajos y regalos si recetan determinados productos; vinculando profesionales médicos destacados con honorarios por consultorías; invitaciones a congresos en diferentes partes del mundo o el financiamiento de investigaciones de poco valor científico o se confabulaciones para hacer negocios donde se inventan o exageran los riesgos sanitarios.

Vince Parry es un profesional del marketing domiciliado en Manhattan y especializado en ayudar a las compañías farmacéuticas como Lilly, es decir a fabricar enfermedades como el mismo lo define. Más allá de lo que denomina el arte de fabricar enfermedades, Parry afirma que las compañías farmacéuticas a menudo congregan a los actores principales (líderes de opinión, médicos locales y grupos de pacientes) para ayudar a definir, poner a punto y fabricar nuevas enfermedades; al juntarlos se fomenta un consenso sobre la enfermedad, la relevancia de esta y las mejores vías para tratarla. Para Parry un objetivo común de su trabajo de marketing consiste en concederle importancia a una enfermedad que solo afectaba a niños. Últimamente se ha hecho un gran esfuerzo para considerar que los adultos también sufren, explica que las personas tienen los mismos problemas en el trabajo en el caso de los adultos, que los que tenían en la escuela en el caso de los niños. Así que últimamente se ha estado hablando mucho de volver a enmarcar un debate sobre esta enfermedad, tal vez de dividirla en una enfermedad infantil y en una enfermedad de adultos. Se ha incrementado el nivel de concientización sobre algo que ni siquiera sabemos si tenemos hasta que empecemos a investigar más (1).

Las deliberaciones de Vince Parry (2) acerca de cómo las compañías farmacéuticas amoldan la percepción de la gente sobre las enfermedades no tienen precio, porque las estrategias a menudo se ocultan de la vista pública. Los hombres y mujeres como los expertos en publicidad, marketing $y$ relaciones públicas, con elegantes oficinas en el centro de Manhattan, Londres, Toronto o Sídney, cobran básicamente por cambiar la percepción que tenemos de nuestros cuerpos, nuestra salud y las enfermedades que supuestamente padecemos. Los mensajes sobre fármacos que salen de estas oficinas de marketing se camuflan en forma de ejercicios de concientización y luego se transmiten a diestra y siniestra a través de campañas de marketing gigantescas, financiación de formación médica y campañas de relaciones públicas de gran impacto mediático. Lo esencial de muchas de estas actividades de concienciación son los grupos de pacientes financiados por la industria. Según Parry, hay pocas dudas de que las compañías farmacéuticas estén al mando de lo que él denomina fabricar enfermedades ya que él trabaja para estas entidades (2).

\section{EL PODER DE LA INDUSTRIA FARMACEUTICA.}

Actualmente la industria dedicada a la fabricación y comercialización de medicamentos tiene una gran influencia sobre 
ciertos ámbitos de relevancia relacionadas a la salud. En la política cuando se toman decisiones sanitarias no siempre se hacen teniendo en cuenta los criterios médicos, en muchos casos las políticas de salud no están dirigidas a una administración responsable y eficaz de las enfermedades, sino más bien al incremento en las ventas de los medicamentos que favorecen principalmente a las compañías que las producen. La presión de la industria sobre los países en el mundo se sustenta en la introducción de gente muy preparada en la política y cuya función es encontrar mecanismos que le permitan a una empresa de medicamentos comercializar mejor sus productos ya sea pasando por encima de los órganos reguladores 0 estableciendo normas o leyes para su introducción al mercado de un país (3). Uno de los métodos de influencia política se da a través de los llamados "lobby" que puede ser denominado como el enganche que se realiza dentro del congreso de una república para el favorecimiento de una compañía. En el 2002, en Estados Unidos se empleaba a 675 "lobbistas", procedentes de 138 empresas, con un costo de $\$ 91$ millones cuya función era promocionar los intereses de sus compañías. La propia PhRMA tiene la sede central de su compañía también en Washington y entre los antiguos miembros del Congreso y otros 342 antiguos altos cargos. El caso del senador Hatch es ilustrativo en el conflicto de intereses que entre los años 1991 y 2000 fue el senador que más subvenciones recibió de la industria farmacéutica además de ser el principal defensor de los intereses de la industria en el Senado (4).

Las contribuciones de las grandes compañías de fármacos suelen ser muy generosas con las campañas políticas como en los años 1999 y 2000 en Estados Unidos, donde se donaron 20 millones de dólares en forma de contribución directa para este fin, además de otros 65 millones en créditos, cuyos beneficiarios van desde partidos políticos hasta grupos y organizaciones de base (5).
La lista de los favores conseguido en los congresos de diferentes países es muy larga, en función a esto mencionaremos solo algunos puntos:

- Extensión de los monopolios, favoreciendo el predominio de una compañía farmacéutica.

- Reducciones fiscales sobre los beneficios, donde se reducen los impuestos a los medicamentos que ingresan a un país $y$ estos son vendidos como si hubieran pagado el impuesto correspondiente.

- Prohibición para la importación de medicamentos de prescripción procedentes de otros países, excepto a los propios fabricantes (1987).

- Establecimiento de leyes y normas a favor de la comercialización de medicamentos (5).

- Presión sobre los órganos reguladores para facilitar la salida de medicamentos al mercado.

- Presión sobre instituciones estatales mediante marchas forzadas donde se busca con celeridad el uso de tratamientos principalmente en el caso de epidemias (5).

El ámbito académico dedicado a la investigación y por su conocimiento científico al sector productivo no está ajeno a este suceso. Los laboratorios sacan provecho de los conocimientos y tecnología generada en universidades e institutos de investigación con subsidios estatales y capitales de riesgo, pues estas asumen la incertidumbre de las primeras y costosas etapas del desarrollo de cualquier medicamento. Estas estrechas relaciones han contribuido a la contaminación de la investigación clínica y es evidente el conflicto de intereses en los resultados de los estudios que se realizan para comprobar la eficacia e inocuidad de los nuevos medicamentos a pesar de ser dirigidos por investigadores de primera línea y publicados en las revistas más prestigiosas (5). 
TABLA 1: Ingreso de las principales empresas farmacéuticas en el mundo

\begin{tabular}{llllll}
\hline AÑO 2004 & MAIS DE & Miles de & AÑO 2012 & & \\
\hline EMPRESA & millones & EMPRESA & PAIS DE & Miles de \\
& ORIGEN & ORIGEN & millones \\
\hline Pfizer & E.E.U.U & 46,1 & Pfizer & E.E.U.U & 47,4 \\
Glaxo Smith kline & Reino unido & 31,3 & Novartis & Suiza & 45,4 \\
Sanofi Aventis & Francia & 30,9 & Merk & E.E.U.U & 41,4 \\
Johson\&johson & E.E.U.U & 22,1 & Sanofi Aventis & Francia & 38,3 \\
Merk & E.E.U.U & 21,5 & Roche & Suiza & 37,5 \\
Astrazeneca & Reino unido & 21,4 & Glaxo Smith kline & Reino unido & 33,1 \\
Novartis & Suiza & 18,5 & Astrazeneca & Reino unido & 27,0 \\
Bristol Myers & E.E.U.U & 15,4 & Johson\&johson & E.E.U.U & 23,5 \\
Wyeth & E.E.U.U & 13,9 & Abbott labs & E.E.U.U & 23,1 \\
Abbott labs & E.E.U.U & 13,7 & Elllilly & E.E.U.U & 18,0 \\
\hline
\end{tabular}

Fuente: PharmExec 2013

\section{CONFESIONES DE UNA EX REPRESENTANTE DE LA INDUSTRIA FARMACEUTICA}

Gwen Olsen, autora del libro "confesiones de una ex representante de la industria farmacéutica", fue una representante de ventas de empresas como Johnson \&Johnson, Bristol-Myers Squibb y Abbott Laboratories, con 15 años de experiencia en la industria farmacéutica y cuya salida del sector fue el año 2000 (6). Su objetivo es desmitificar acerca del rol que cumple la industria vinculado a la curación de enfermedades y la salud. Ella refiere que el negocio de la industria de fármacos es la mantención de enfermedades y la administración de síntomas, ellos no están en el negocio de la cura del cáncer, Alzheimer o problemas del corazón, pues de ser así, estarían en el negocio de quedarse sin negocio. Es demostrable que la industria no quiere curar a la gente porque gran parte de los fármacos producidos en el mundo permiten a la gente seguir siendo dependientes y de hecho se le dirá a un paciente cuando le recetan un ansiolítico, antidepresivo 0 antipsicótico que probablemente tenga que usarlo por el resto de su vida. Mucha gente se da cuenta que está usando fármacos durante mucho tiempo de manera permanente y los problemas continuarían si dejaran de consumir de golpe e incluso paulatinamente un medicamento como el caso de los fármacos para reducir el colesterol cuyos efectos colaterales es la aparición de otras enfermedades. También el uso de placebos que son pastillas de azúcar y que incluso muchos medicamentos no son más que los placebos como el caso particular del reciente ensayo en el Reino Unido sobre antidepresivos (inhibidores de serotonina selectiva) donde se demostró que los antidepresivos no son más efectivos que un placebo, sin embargo son más de 44 millones de personas que las han utilizado (5). Existen muchas cosas que se pueden hacer por los pacientes deprimidos para mejorar su estado mental, pues un estudio demostró que el ejercicio es más efectivo que un placebo o antidepresivo. Se sabe que las empresas de los medicamentos ganan 5 a 6 veces más que cualquier otra empresa en los Estados Unidos y es difícil pensar que las grandes compañías renuncien de buena manera a esos beneficios, pues nosotros estamos considerados como mercancía humana, alentados por muchos médicos engañados por estas empresas al no considerar las 
consecuencias de los pacientes, no conocer la información que están distribuyendo ni darse cuenta de los efectos secundarios ocultos en los medicamentos. Debemos recuperar el control que la industria ha tomado sobre nosotros y exigir la responsabilidad por sus acciones y productos defectuosos que ponen en el mercado. Necesitamos educarnos y saber que existen opciones que son más efectivas que los fármacos como el aspecto nutricional de la dieta y el estilo de vida, ejercitándonos y cuidando nuestra salud porque una vez que comenzamos a tomar un medicamento tras otro, seremos dependientes de por vida (5).

\section{LA VERDAD SOBRE LA INDUSTRIA FARMACÉUTICA. COMO NOS ENGAÑAN Y QUE HACER AL RESPECTO}

Este es un libro escrito por Marcia Angell MD donde después de 17 años como editora de la revista the New England Journal of Medicine, decide ajustar cuentas con el Big Pharma (la gran industria farmacéutica) mediante la publicación de un libro en el cual desentraña los mecanismos que la industria de los medicamentos utiliza para controlar el mercado farmacéutico, el poder de los políticos, las voluntades de los médicos, e incluso las opiniones de la población en general. Se trata de un libro de denuncia, en el que se analiza la situación actual del consumo de medicamentos de prescripción en los Estados Unidos de América (EUA), pero que puede extrapolarse a grandes rasgos a la situación de la mayoría de países occidentales. Su lectura es recomendable para toda la sociedad, especialmente para aquellos que estén interesados en conocer todo lo que está detrás de este negocio. A continuación se muestra un resumen de los puntos más importantes del libro:

- El tiempo medio de prueba que requiere un medicamento para salir al mercado es de 6-7 años y el tiempo que la Food and Drug Administration lo aprueba o rechaza es de 16 meses. Este tiempo siempre fue considerado excesivo por la industria farmacéutica, la cual en la década de los noventa consiguió a través de la presión sobre los políticos y los medios de comunicación afines, que la Food and Drug Administration acelerara el tiempo medio de revisión de sus expedientes, pasando de la agencia más lenta a la más rápida en tramitar expedientes (4).

- Entre los años 1998 y 2002 se aprobaron 415 nuevos medicamentos, donde sólo 133 eran nuevos medicamentos 58 fueron medicamentos innovadores. Pero el auténtico escándalo es que la mayor parte de estos suelen proceder de investigación financiada con fondos públicos realizadas en universidades 0 empresas de biotecnología en aplicación a la ley BayhDole de 1980 donde se permitió a las universidades patentar los descubrimientos de investigación médica y vender los derechos a las empresas farmacéuticas, cobrando así en concepto de royalties una cantidad que suele ser un porcentaje fijo sobre las ventas lo cual se registra como cifras exorbitantes de dinero. Este ha sido el caso del Taxol ${ }^{\circledR}$ (paclitaxel) utilizado en el cáncer de mama, ovario y pulmón registrado como el mayor éxito de ventas en la historia de la terapia antineoplásica, el Epogen® (eritropoyetina) utilizada para el tratamiento de la anemia en pacientes con insuficiencia renal crónica y el Gleevec® (imatinib) utilizado para un raro tipo de leucemia, la mieloide crónica que es propiedad de Novartis (5).

- La estrategia de comercialización de los "me-too-drug" (medicamentos iguales a productos anteriores que son vendidos como nuevas fórmulas) deriva como necesidad del propio laboratorio fabricante de comercializar una alternativa para un medicamento cuya patente está a punto de expirar, pero también por el deseo de la competencia de hacerse con una parte de la cuota del mercado de un determinado medicamento (5). 
- A partir de 1995 los investigadores del Instituto Nacional de Salud americano (NIH) pudieron recibir honorarios y opciones de compra de acciones por actividades de consultoría procedentes de empresas farmacéuticas con las cuales habían desarrollado acuerdos de colaboración. Un caso particular es la del director del laboratorio de Inmunología del $\mathrm{NIH}$ que recibió a lo largo de 11 años de ejercicio $\$ 1.4$ millones en concepto de asesoría y opciones de compra de acciones por valor de 865000 dólares. El resultado es que en el año 2003, el 93\% de los 2259 más destacados científicos de la agencia no declararon los ingresos que recibían de actividades ajenas a la propia agencia (4).

- Existe además una variedad de alteraciones en los ensayos clínicos de los nuevos medicamentos que incluye la eliminación de resultados negativos favoreciéndolos como fue el caso de Celebrex®, en el cual se publicaron en la revista JAMA sólo los resultados favorables de los primeros seis meses del estudio y no el estudio completo de doce meses para la observación de efectos secundarios. También es el caso de Remune (Inmune Response Corporation), una empresa dedicada a la biotecnología que firmó en 1996 un convenio con la Universidad de California para realizar un Ensayo Clínico con este nuevo medicamento para el tratamiento del $\mathrm{VIH}$ y que después de tres años de estudio se comprobó que era infectivo (4).

- En el 2001 las compañías farmacéuticas entregaron a los médicos muestras de medicamentos por un valor de $\$ 11000$ millones, sobretodo nuevos y caros medicamentos "me-too-drug". Estas muestras se denominan "gratuitas", pero en realidad no lo son ni para el médico ni para el paciente, ya que el costo del regalo va incluido en el precio final del producto. Durante ese mismo año 88000 visitadores médicos americanos entablaron contacto con los médicos. La industria farmacéutica afirmó gastar $\$ 5500$ millones en esta actividad, cantidad que parece baja ya que al realizar el cálculo, el costo total real de los sueldos de los visitadores asciende a 62500 millones de dólares (4).

- Los gastos en promoción de medicamentos se dan principalmente en acontecimientos importantes como el caso del Levitra ${ }^{\circledR}$ de la compañía Glaxo que firmó un acuerdo de promoción con la Liga Nacional de Fútbol Americano (National Football League) por un valor de 20 millones de dólares para que el producto aparezca en los estadios de fútbol americano. Eli Lilly's incluyó el logotipo de Cialis $\AA$ (medicamento para la impotencia) en un barco de la Copa América (4). Otra modalidad de promoción es pago a celebridades realizar entrevistas en la televisión sobre las enfermedades y sus tratamientos como el caso de Lauren Bacall que recibió dinero por citar en un programa televisivo la degeneración macular de un familiar suyo y recomendar abiertamente el uso de Visudye ${ }^{\circledR}$ de Novartis. En la publicidad dirigida al consumidor aumentó en tres entre los años 1997 y 2001 . El incremento dedicado a la televisión pasó del $25 \%$ al $64 \%$ del total dedicado al publicidad del consumidor favorecido por un cambio en las normas de emisión de publicidad en 1997 por la Food And Drug Administration, de tal manera que la empresa anunciante de un medicamento ya no estaba obligada a informar de todos los riesgos que podía causar su toma, sino sólo los más importantes (4).

- En el 2001 la industria farmacéutica empleaba en los Estados Unidos una legión de88 000 visitadores médicos, a razón de uno por cada 4-5 médicos en ejercicio. En general se trata de profesionales jóvenes con toda una serie de regalos y deferencias cuyo resultado 
suele ser especialmente eficaz. Otra modalidad de visita médica es el pago que un laboratorio realiza en varios cientos de dólares por permitir que un logotipo de medicamento acompañe al médico mientras visita a sus pacientes, con la finalidad de "recoger información útil" (4).

- Los sobornos a los médicos son frecuentes. El caso de Lupron $\AA$ en Estados Unidos es todo un ejemplo. Este medicamento fue comercializado en 1990 por la empresa TAP Pharmaceuticals para el tratamiento del cáncer de próstata, administrándose en las consultas de los médicos en un $80 \%$ de los casos a cargo del sistema público Medicare. En 1996 apareció un competidor, Zoladex® de Aztrazeneca que para intentar mantener la fidelidad de los médicos el fabricante de Lupron® comenzó a venderles el producto a un precio falso (los médicos lo adquirían a $350 \$$ cada tratamiento pero la empresa extendía una factura por un valor de 500\$, que era la cantidad Medicare reembolsaba a los médicos) (4).

- En 2001 la compañía General Electric con la financiación de la industria farmacéutica creó el canal de televisión "The Patient Chanel" que mostraba programas de medicina intercalado con publicidad de medicamentos en las salas de espera y habitaciones de hospitales. En el plazo de un año, más de ochocientos hospitales americanos estaban conectados a este canal que emitía la señal sin interrupción durante veinticuatro horas, siete días a la semana. El objetivo declarado de la compañía era la educación sanitaria de los pacientes. Sin embargo la administración sanitaria de la industria farmacéuticas y manifestó en contra de este canal porque consideraba que en él no se podían distinguir las actividades educativas de las de promocionales (4).

- Según la legislación actual, la patente de un producto tiene una validez de 20 años aplicada tanto a la sustancia, método de uso para una determinada enfermedad, formulación o proceso de manufacturación. Anteriormente para ser patentado un producto debe demostrar ser útil, novedoso y relevante, sin embargo a partir de 1980, los requisitos para registrar patentes disminuyeron, de tal modo que los inventos no tenían que demostrar su utilidad, sino que simplemente el supuesto invento debía tener utilidad para futuras investigaciones. Además, con la creación en 1982 de un tribunal especial para atender las apelaciones por la denegación de solicitud de patentes, el registro de medicamentos ha aumentado considerablemente por Oficina de Patentes y Marcas de los Estados Unidos (USPTO) (4).

- Las medidas que han favorecido la expansión de los monopolios son el resultado de una serie de leyes y disposiciones aprobadas desde 1980 favorables a la industria farmacéutica donde el período de exclusividad sobre los medicamentos se ha extendido hasta extremos absurdos. El aumento de las demandas entre compañías, amparándose en la ley Hatch-Waxman donde las compañías pertenecientes a este rubro comenzaron a demandar a las compañías que solicitaban comercializar un genérico, alegando que aún existía alguna patente activa para su medicamento de marca. Con esta estrategia automáticamente se conseguía prolongar los derechos de exclusividad del producto durante 30 meses más (el período estimado de duración del proceso judicial) (4).

- La Ley de libre prescripción para el uso de medicamentos de 1992 autorizaba a las Compañías a donar fondos a la Food and Drug Administration, con la finalidad de acelerar los trámites para la aprobación de un determinado medicamento. De hecho, desde la aprobación de la ley se ha batido el récord de medicamentos retirados del 
mercado por motivos de seguridad (13 en total) que causaron miles de muertos. Pero la rapidez para aprobar un medicamento contrasta con la lentitud en retirar un medicamento del mercado cuando empiezan se originan dudas sobre su seguridad. Por ejemplo, Rezulin $\AA$, un medicamento para la diabetes, fue retirado del mercado en Gran Bretaña en 1997 por ocasionar insuficiencia renal, pero en los Estados Unidos no se retiró hasta dos años y medio después, momento en el que ya había causado 63 muertes (4).

- El caso de Prilosec® (omeprazol) de AstraZeneca es muy ilustrativo, ya que en el 2001, cuando su patente iba a caducar, era el medicamento más vendido del mundo, un auténtico record en ventas con 6000 millones de dólares anuales. Para tratar de compensar la pérdidas derivadas de la aparición de genéricos, el propio laboratorio comercializó Nexium® (esomeprazol), que en realidad no es más que la mitad de Prilosec®, ya que en su composición se eliminó el isómero inactivo de la molécula original (4).

- El caso de Clarinex® (desloratadina) de Schering-Plough's es similar. Este medicamento no es más que el metabolito activo de Claritin $\AA$ (loratadina), este producto fue un éxito en ventas del mismo laboratorio en el 2001 que generaba una ventas por 2700 millones de dólares, cuya patente iba a caducar en 2002. Este caso es más curioso aún, ya que el propio laboratorio fabricante había patentado en 1987 el principio activo de Clarinex®, pero no solicitó su aprobación por la Food and Drug Administration hasta 2001. Para mantener los ingresos, el laboratorio fabricante, consciente de que no suponía avance alguno, lo comercializó a un precio ligeramente inferior al de su antecesor (4).

\section{Medicamentos Que Matan Y Crimen Organizado.}

Este título hace referencia al último libro escrito por el danés Peter C. Gotzsche, uno de los libros más impactantes y publicados sobre la corrupción de las compañías farmacéuticas vinculados con médicos, academias, sociedades científicas, organizaciones de pacientes, líderes de opinión, agencias reguladoras de medicamentos, revistas, políticos, gobiernos, periodistas y agencias de medicamentos. El conocimiento de Gotzsche sobre las compañías farmacéuticas se inicia desde sus primeros años de trabajo en la misma industria farmacéutica antes de convertirse en el director del Centro de la Biblioteca Cochrane en los países nórdicos, con sede en Copenhague (6).

\section{Medicamentos que nos enferman e industrias farmacéuticas que nos convierten en pacientes.}

Este es un libro escrito por Ray Moynihan y Alan Cassels considerado un best seller. Ray Moynihan es un escritor periodista especializado en temas de salud, colaborando asiduamente con la British Medical Jounal, the Lancet, la Australian Finantial Review. Alan Cassels es un investigador y escritor canadiense que ha centrado su trabajo en políticas farmacéuticas. En este texto se explica con claridad, los medicamentos que nos enferman, revela cómo se transforman en enfermedades de la vida cotidiana no necesariamente patológicos; los cambios de humor, la menopausia, la timidez, la presión alta, osteoporosis, etc. El resultado es una gigantesca expansión de un mercado que genera enormes beneficios a partir del viejo sueño de convertir a personas sanar en pacientes que consumen fármacos sin necesidad (1). Sin embargo para la gente relativamente sana, un diagnóstico erróneo y un medicamento pueden suponer claras desventajas, costos importantes y un riesgo real de padecer posibles efectos secundarios 
mortales. Este vasto terreno se ha convertido en el nuevo mercado mundial de pacientes potenciales, objetivo clave para los presupuestos promocionales de la millonaria industria farmacéutica (1).

\section{ESTUDIOS DE GRAN IMPORTANCIA}

\section{El estudio KESSLER}

Este fue un conjunto de estudios realizado por el Dr. Kessler y un grupo de médicos. Uno de los últimos estudios de kressler incluía sondeos en catorce naciones, dirigido entre los años 2001 y 2003. El sólido proyecto fue financiado por muchas organizaciones públicas y privadas, incluidas lilly, GSk y Pfizer, aunque los sondeos se llevaron a cabo guardando las distancias con sus patrocinadores. Este estudio internacional declaró que el $26 \%$ de la gente en Estados Unidos responde a los criterios que la definen como paciente de un trastorno mental, en México se obtuvo el $12 \%$, en china y Japón es el $9 \%$ y en Italia del $8 \%$. Sin embargo, todo aquello calificado como trastornos mentales en muchos estudios anteriores, gran parte eran en realidad casos leves según las definiciones del estudio lo cual significa que tal vez los tratamientos en estos casos no eran justificados y en la mitad de aquellos pacientes clasificados con trastornos graves no recibieron el tratamiento médico que requerían, es decir, se realizó la prueba del infratratamiento. El estudio internacional también demostró que al menos la mitad de las personas en tratamiento probablemente no lo necesiten.

La reseña del estudio publicada en el Journal of American Medical Association por Kessler y su grupo de médicos, afirman que la mayoría o casi la totalidad de las personas en tratamiento en cada país son o bien casos leves o bien no son casos de ningún tipo. La obsesión general de las necesidades no cubiertas es una noción constantemente promocionada por médicos y compañías farmacéuticas para justificar la agresividad del marketing de fármacos que puede estar creando un nuevo y extraño fenómeno (cubrir a los que necesitan). Uno de los programas educativos que promovió enérgicamente la idea de las necesidades no cubiertas se difundió en Australia en la década de los 90 donde grupos de médicos generalistas que asistían a encuentros de formación médica permanente fueron informados de que un tercio de las personas que visitaban sus consultas padecían una enfermedad mental y se les instó a ser más agresivos a la hora de detectar y tratar la depresión (1).

\section{El estudio ALLHAT}

Existe un gran estudio de larga duración que compara varios fármacos sustentada en el estudio de terapia hormonal sustitutiva de la Women's Health Initiative, patrocinada por el gobierno de EEUU con la industria farmacéutica. En este proyecto participaron más de 40000 personas y fue presidido por el Dr. Curt Furberg. Este histórico estudio comparó cuatro tipos diferentes de fármacos, incluyendo los más viejos y baratos, así como los últimos en salir y los más caros. Los medicamentos se cotejaron en términos de su efectividad en la reducción de las enfermedades cardiacas, de su seguridad y de su relación en el costo beneficio. En este estudio se demostró que no sólo los fármacos más baratos y antiguos (los diuréticos de dosis bajas o tiazidas) cumplían su cometido tan bien como los nuevos y caros en cuanto a la reducción de la probabilidad de sufrir ataques cardiacos y apoplejías sino que resultaron ser ligeramente superiores porque eran un poco mejores en cuanto a la prevención de la insuficiencia cardiaca. Estos fármacos antiguos le ganaron a los nuevos puesto que están disponibles como genéricos con un tratamiento tan barato que es prácticamente gratuita. En Canadá se ha estimado que tomar una dosis diaria de diuréticos durante diez años puede costar apenas cuarenta dólares canadienses, mientras que los nuevos medicamentos como el popular Norvasc, podrían costar hasta doscientas veces más. Las conclusiones de este histórico estudio se publicaron en un 
artículo del Journal of the American Medical Association (JAMA): los diuréticos resultaron superiores en la prevención de uno o más tipos de enfermedades cardiacas y menos caras (1).

\section{CASOS VERGONZOSOS EN EL NEGOCIO DE LA ENFERMEDAD Y LA LISTA NEGRA DE LOS MEDICAMENTOS QUE SE DEBEN EVITAR.}

A nivel mundial existe un gran número de casos en materia de denuncias frecuentes en contra de las más importantes corporaciones de la industria farmacéutica. Estas denuncias que incluyen casos desde la venta de medicamentos placebo que no tienen ningún efecto sobre la salud de las personas y que son vendidas como medicamentos exitosos en la cura de enfermedades de importancia hasta los casos de toxicidad o efectos colaterales de muchos fármacos que ponen en gran riesgo la salud de las personas. Tal vez el caso más relevante en los últimos años es el de la gripe A o influenza (mal llamada gripe porcina) cuyo origen se reportó en abril del 2009 con la primera muerte de una mujer en México. Esta enfermedad pudo extenderse rápidamente hacia EEUU, Canadá y luego a Europa y Asia por lo que la OMS advierte el posible riesgo de una pandemia tras la muerte de 7 personas más en México. En mayo del mismo año, la OMS y las farmacéuticas se perfilan en un plan de vacunación a nivel global, estableciéndose el 11 de junio una pandemia mundial por Gripe A declarada por la OMS (3). El 4 de junio del 2010, la British Medical Journal (BMJ) y el Consejo de Europa criticaban a la OMS por supuestos conflictos de intereses por la existencia de un protocolo de diez años antes para una enfermedad reciente. En el citado artículo de la BMJ muestra un informe clave donde revela que la OMS ocultó los vínculos financieros entre sus expertos y las farmacéuticas Roche y Glaxo (fabricantes de Tamiflu y Relenza usados contra el virus H1N1). Ese fue el informe que instó a los Gobiernos adquirir reservas de esos medicamentos por $\$ 6000$ millones. Ante esto se suma el informe de los ingresos de Roche que en el año 2012 pasó a ser una de las cinco primeras compañías (3).

También se han registrado diversos casos de directores de diversas clínicas en Europa realizando ensayos clínicos no éticos en pacientes psiquiátricos hospitalizados o legalmente incapaces, a fin de probar medicamentos prohibidos a cambio de elevados honorarios por empresas farmacéuticas (7). En Asia y África se han experimentado en miles de mujeres embarazadas con $\mathrm{VIH}$ quienes recibieron un placebo en lugar del fármaco probado, financiados principalmente por el programa conjunto de las Naciones Unidas sobre el VIH (7). Además del caso de médicos alemanes, austriacos, italianos y norteamericanos que extrajeron tejidos musculares y pulmonares de personas con lesiones graves sin autorización, para probar la acción del Trasylol, adulterando las tasas de mortalidad por el uso de este medicamento (7).

El 31 de enero del 2013, La revista francesa de medicina "Prescrire", publicó una lista de los medicamentos más peligrosos en el cual se recomienda su retiro del mercado debido a los riesgos sanitarios que representan con relación a los beneficios aportados. Esta lista ha tuvo como base los análisis publicados en la revista entre el 2010 y 2012. 
TABLA 2. Lista de los medicamentos más peligrosos

\begin{tabular}{|c|c|}
\hline Área & Medicamentos \\
\hline Cardiología & $\begin{array}{l}\text { Aliskiren (Rasilez), Fenofibrato (Lipanthyl), Bezafibrate (Befizal), } \\
\text { Ciprofibrate (Lipanor), Ivabradina (Procoralan) } \\
\text { Nicorandil (Adancor), Trimetazidina (Vastarel), Dihidroergocristina } \\
\text { (Vasobral), Cafedrina + theodrenaline (Praxinor), Exforge }\end{array}$ \\
\hline Oncología y hematología & $\begin{array}{l}\text { Catumaxomab (Removab), Panitumumab (Vectibix) } \\
\text { Trabectedina (Yondelis), Vandenatib (Caprelsa), Vinflumine (Javlor) }\end{array}$ \\
\hline Dermatología & Tacrolimus (Protopic), Mequitazina (primalan), Prometazina inyectable. \\
\hline Diabetes y nutrición & $\begin{array}{l}\text { Saxagliptina (onglyza), Sitagliptina (Januvia, Xelevia), Vildagliptina } \\
\text { (Galvus), Orlistat (Xenical) }\end{array}$ \\
\hline $\begin{array}{l}\text { Gastroenterología } \\
\text { Infectología } \\
\text { Neurología }\end{array}$ & $\begin{array}{l}\text { Domperidona (Motilium), Prucaloprida (Resolor). } \\
\text { Moxifloxacina (Izilox), Telitromicina (Ketek). } \\
\text { Flunarizina (Sibelium), Natalizumab (Tysabri), Tolcapona (Tasmar) }\end{array}$ \\
\hline Psiquiatría & $\begin{array}{l}\text { Agomelatina (Valdoxan), Duloxetina (Cymbalta), Milnacipran (Ixel), } \\
\text { Tianeptina (Stablon), Venlaxatina (Effexor), Asenapina (Sycrest), } \\
\text { Etifoxina (Stresam), Meprobamato, Bupropion (Zyban), Pirfenidona } \\
\text { (Esbriet), Tixocortol (combinado con Clorhexidina en Thiovalone). }\end{array}$ \\
\hline Reumatología & $\begin{array}{l}\text { Coxibs: Celecoxib (Celebrex), Etoricoxib (Arcoxia), Parecoxib (Dynastat), } \\
\text { Floctafenina (Idarac), Ketoprofen en gel (Ketum), Nefopam (Acupan), } \\
\text { Nimesulida (Nexen), Piroxicam (Feldene) }\end{array}$ \\
\hline $\begin{array}{l}\text { Osteoporosis } \\
\text { Artrosis }\end{array}$ & $\begin{array}{l}\text { Denosumab (Prolia), Stronium ranelate (Protelos), Teriparatida (Forsteo). } \\
\text { Diacerina (ART 50), Glucosamida (Voltaflex). }\end{array}$ \\
\hline
\end{tabular}

Fuente: Revista francesa "Prescrire"

\section{LOS EXPEDIENTES NO AUTORIZADOS DE LOS GIGANTES DE LOS MEDICAMENTOS}

\section{El expediente Sanofi-Aventis}

- Efectos secundarios graves. En el año 2005, 1700 mujeres españolas demandan a Sanofi-Aventis por ocultar información sobre efectos secundarios graves. En Junio del 2011, El Tribunal Supremo ratifica una sentencia de la Audiencia de Barcelona por la que Sanofi Aventis deberá indemnizar a tres afectadas (8).

\section{El expediente Pfizer}

- Fraude y comercialización ilegal de 4 fármacos. En setiembre del 2009, Pfizer se declara culpable de fraude a la salud, calificado como el más grande en la historia de los EEUU y recibe la mayor multa penal jamás impuesta por la comercialización ilegal de 4 de sus fármacos (Bextra, Geodon, Zyvox y Lyrica) (8).

- Lobby contra TLC con Nueva Zelandia y desestabilización de su Ministra de Salud. En el Año 2010 Pfizer Invierte \$ 17 millones en el Congreso de EEUU, para obtener la oposición parlamentaria al TLC con Nueva Zelandia, a causa de su política sobre medicamentos. Según cables filtrados por Wikileaks. Buscaron hacer renunciar a la entonces Ministra de Salud, Helen Clark, para lo cual desabastecieron de medicamentos a Nueva Zelandia (8).

- Muerte y daños cerebrales irreversibles en niños de Nigeria por suministro de droga sin ensayo ni autorización sanitaria. En Agosto del 2011, Pfizer es condenada a pagar $\$ 175.000$ a cada familia de los 4 
niños nigerianos muertos durante un ensayo ilegal de droga contra la meningitis y otras 200 familias esperan una indemnización. El fármaco no tenía ensayos clínicos en seres humanos (8).

- Desarrollo de Virus genéticamente modificados. En enero del 2012, El juez Warren Eginton condena a Pfizer a pagar \$ 2.3 millones a la Dra. en biología molecular Becky Mc Clain, ex-trabajadora de la compañía infectada por un virus genéticamente modificado que puede conducir al síndrome de inmunodeficiencia adquirida o SIDA (8).

\section{El expediente Gilead Science}

- Campaña de desprestigio contra la compañía india fabricante de genéricos anti SIDA. En agosto del 2007 este hecho fue realizado por la ONG norteamericana, AIDS Healthcare Foundation (AHF), parcialmente financiada por Gilead. Los Anuncios en los principales periódicos indios acusaron a la empresa Cipla de vender Viraday (retroviral anti-SIDA) más caro en la India que en África. Cipla indicó no haber vendido ni un solo paquete de Viraday en África (8).

- Influencia para el combate la Gripe Aviar. En 1999 el medicamento Tamiflu es aprobado para el tratamiento de la influenza. Donald Rumsfeld, presidente de la compañía desde 1997, en enero del 2001 fue nombrado Secretario de Defensa de EEUU por mandato de George W. Bush. Este hecho disparó las acciones de la compañía puesto que George W. Bush insta al Congreso a aprobar $\$ 7100$ millones en fondos de emergencia para la pandemia de gripe aviar a pesar de su eficacia no comprobada del Tamiflu contra la influenza (8).

- Fármaco sin eficacia comprobada. tratamiento recomendado por la OMS para la leishmaniasis visceral (ETD). La literatura científica duda de la eficacia del fármaco, sin embargo la licencia para comercializar dicho producto es hasta el 2016 y actualmente se ha comprobado que la anfotericina $B$ posee graves efectos secundarios asociados a la nefrotoxicidad, hepatotoxicidad, anemia, leucopenia, entre otras que incluyen problemas cardiacos serios (8).

- Influencia para el combate la Gripe Aviar. En 1999 el medicamento Tamiflu es aprobado para el tratamiento de la influenza. Donald Rumsfeld, presidente de la compañía desde 1997, en enero del 2001 fue nombrado Secretario de Defensa por George W. Bush. Este hecho disparó las acciones de la compañía puesto que se instó al congreso la aprobación de $\$ 7$ 100 millones en fondos para la pandemia a pesar de su eficacia no comprobada del Tamiflu contra la influenza (8).

\section{El expediente Johnson \& Johnson (J\&J).}

- Retiro 43 medicamentos por contaminación. En abril del 2010 tras una inspección de la Food and Drug Administration se reportó la contaminación de ingredientes, maquinaria sucia e irregularidades en las medidas de algunos medicamentos (8).

- Fraude y comercialización ilegal de fármacos. En el 2010, J \& J acordó pagar una multa de $\$ 81$ millones por la comercialización del Topamax, para prevenir la migraña, epilepsia, etc (8).

- Retiro de productos para bebés por uso de cancerígeno. En marzo del 2009 la Food and Drug Administration (EEUU) incluye varios productos para bebés muy vendidos que utilizaban el 1,4 dioxano, posible carcinógeno para los humanos y tóxico para el cerebro, el sistema nervioso central, los riñones e hígado", según la Environmental Protection Agency (8).

\section{El expediente Merck Sharp \& Dohme (MSD)}

- Ocultamiento de efectos secundarios graves seguido de muerte y "homicidio culposo". En Noviembre del 2011, esta 
compañía se declara culpable ante la justicia por fraude y ocultamiento de datos sobre el anti inflamatorio y anti-artrítico Vioxx con una multa de $\$ 1271$ millones. En agosto del 2005 se le declarada responsable de la muerte de Robert Ernst, existiendo otras 5000 denuncias por el mismo caso por el Vioxx en los programas de salud estatales "Medicaid" (8).

- Vínculo entre el fármaco y ataques al corazón seguidos de muerte. Investigaciones independientes publicadas por Archives of Internal Medicine demostraron el vínculo entre el fármaco y los ataques al corazón seguidos de muerte. Se calculan en casi 28000 muertos por los efectos secundarios de Vioxx, generando ingresos por \$ 2500 millones por año desde 1999 hasta su retiro en el 2004 (8).

- Corrupción, coimas, efectos secundarios graves y muerte en la vacuna contra el Papiloma Humano (VPH). En Septiembre del 2011, la Food and Drug Administration publica informes acerca de la vacuna Gardasil contra el VPH que detallan 3589 casos de reacciones dañinas provocadas por la vacuna, 26 casos de muertes, 213 casos de incapacidad permanente, 25 con diagnóstico de síndrome de GuillainBarré, 789 casos serios diversos entre embolia pulmonar, parálisis, ceguera, pancreatitis, etc. Siendo la tasa de mortandad de niñas que reciben la vacuna contra el VPH, más alta que las muertes que la vacuna evita (8).

- Un estudio publicado en la Annals of Medicine por los científicos Lucija Tomljenovic y \& Christopher A. mostraron que Hasta la fecha, la eficacia de cualquiera de las dos vacunas utilizadas actualmente contra el VPH en la prevención cáncer de cuello uterino no está demostrada aún, al mismo tiempo que los riesgos de la vacuna aún no se han evaluado completamente (8).

\section{El expediente Novartis}

- Creación de virus y agentes patógenos para implementar en la vacuna de la Gripe H1N1 (anteriormente llamada gripe porcina). Varios autores son sindicados como involucrados a las compañías Novartis y Baxter en la creación de virus y agentes patógenos para la implementación en la vacuna de la Gripe H1N1 (8).

- Biopiratería de la planta tradicional china contra la malaria y la responsabilidad de muertes por omisión y negligencia. En el 2001, La OMS firma un acuerdo con Novartis hasta el 2005 para 60 millones de tratamientos con Coartem basada en la planta Artemisa annua usada en la medicina china contra la malaria por su alta efectividad. Finalmente Novartis no realizó la inversión prometida permitiendo que la enfermedad causara la muerte de millones de personas en los últimos años (8).

- Intoxicaciones por Herbicida altamente venenoso. Un estudio publicado por la secretaría del Convenio de Rotterdam en el 2010, muestra que 54 de 296 intoxicaciones por plaguicidas son causados por el Gramoxone (paraquat), creado con AstraZeneca y vendido en más de 100 países (8).

- Guerra comercial contra remedios genéricos más baratos. Novartis presenta una oposición contra la decisión y otra contra la Ley de Patentes en la India, alegando que viola la Convención Internacional para la Protección de los Derechos de Propiedad Intelectual y imponiendo a modificar su ley de patentes por el acuerdo de la Organización Mundial del Comercio (el mesilato de imatinib contra el cáncer de sangre cuesta en la India $\$ 2500.00$ y el precio del genérico es de \$175.00) (8).

- En octubre del 2005, La revista Science publicó la reconstrucción total in vitro de un virus extinto (virus de la gripe española 
de 1918 - H1N1) a partir del análisis de muestras de tejidos por el Dr. Jeffrey Taubenberger en el Centro para el Control y Prevención de Enfermedades de Atlanta (EEUU). Al igual que el original, el virus reconstituido mató en pocos días a ratones y embriones de pollo. Se descubrió que en 1918, genes del virus de la gripe humana y la gripe aviar se mezclaron generando una enorme pandemia. El documento publicado por Science fue elegido como "El documento del Año" (8).

- El 4 de Noviembre del 2005, Novartis obtiene la patente de una "vacuna contra la gripe con coadyuvantes". La solicitud de patente se produce un mes después del documento publicado por Science. Medimmune ocupa sus oficinas en la misma calle donde trabajaba el Dr. Taubenberger. La patente es otorgada un mes antes que comenzara la epidemia de Gripe A que derivara en pandemia (8).

\section{El expediente AstraZeneca}

- Ensayos clínicos fraudulentos y ocultamiento de efectos secundarios. En diciembre del 2009, AstraZeneca paga $\$ 738$ millones por daños y perjuicios a unas 17500 personas en EEUU por ocultar gravísimos efectos secundarios de diabetes del Seroquel, su medicamento más vendido con aproximadamente $\$ 5$ mil millones anuales en ventas (antipsicótico a base de fumarato de quetiapina) (8).

- Fraude en Programas de Salud Pública. En Abril del 2010, la compañía fue sentenciada a pagar $\$ 520$ millones por fraude a los programas Medicare, Medcaid y otros dedicados a la atención en salud, financiados por el gobierno de EEUU, en relación con su comercialización para usos no aprobados del Seroquel (8).

- Fraude en elección de Premio Nobel de Medicina. En el año 2008, la unidad anticorrupción de la policía de Suecia determinó fraude en la elección de Haraldzur Hausen, Premio Nobel de Medicina, por sus aportes a la comprensión del Virus del Papiloma Humano (VPH) y el derivado cáncer de útero. AstraZeneca ejerció influencia indebida en la adjudicación puesto que figuras importantes en el proceso tenían fuertes vínculos con dicha compañía (8).

- Manipulación de los precios. En el Año 2010, AstraZeneca acuerda pagar \$ 803 millones en pleitos fiscales en el Reino Unido por manipulación de precios de transferencia el cual es un sistema de contabilidad de las multinacionales que le permite anotar las ganancias de un país de altos impuestos en una jurisdicción de bajos impuestos, reduciendo al mínimo el pago de estos (8).

\section{CONCLUSIONES}

Hace más de 30 años, el director de Merck Henry Gadsden, máximo responsable de una de las empresas farmacéuticas más grandes del mundo, expresó claramente a la revista Fortune su gran preocupación al ver que el mercado potencial de su empresa estaba confinado sólo a las personas enfermas. Gadsden declaró que mucho tiempo soñó con producir medicamentos destinados a la gente sana para tener la posibilidad de que Merck pudiera vender a todo el mundo. Estas palabras suenan realmente indignantes ante la posibilidad de jugar con la salud del mundo con la cual las compañías más importantes han enfocado sus estrategias de mercado, transformando problemas leves de salud en problemas de salud importantes donde continuamente cada vez más las personas sanas se transforman en enfermos afectados por el deterioro físico y mental de la enfermedad. 


\section{BIBLIOGRAFIA}

1. Ray Moynihan y Alan Cassels. Medicamentos que nos enferman e industrias farmacéuticas que nos convierten en pacientes. Primera edición. Madrid, España. Junio del 2006.

2. Ler, de Vince P. "The art of branding a condition ", Medical Marketing \& Media, Londres, 2003.

3. La industria farmacéutica domina los órganos reguladores (entrevista Madrid, España 2012.). Disponible en: http://www.lasexta.com/programas/ salvados/noticias/industria-farmaceuticadomina-organos-reguladores 2013 040700099.html.

4. Arancón F. El poder de la industria farmacéutica. El orden mundial en el siglo XXI. 3 noviembre del 2013. [Internet] Disponible en: http://elordenmundial. com/economia/el-poder-de-la-industriafarmaceutica/.

5. Angell M. La verdad acerca de las compañías de medicamentos. Que hacer al respecto. New York 2004.

6. Olsen G. Confesiones de una representante de la industria farmacéutica. New York. 2005.

7. Confesiones de una ex representante de la industria farmacéutica (video). Gwen
Olsen. Video (8 min). Julio del 2012. Disponible en: http://www.youtube. com/watch? $v=$ wIWuEAFlg1Y

8. Peter C. Gotzsche. Medicamentos que matan y crimen organizado. Como la gran industria corrompió la salud. London 2013.

9. Cortés A. El lado oscuro de la producción y comercialización de medicamentos [Internet]. Colombia médica. Universidad del Valle, Colombia. 2007. Disponible en: http://colombiamedica.univalle.edu.co/ind ex.php/comedica/article/view/517/964

10. Abraham Ender. La industria farmacéutica, expedientes no autorizados. 21 Mayo 2012. [Internet] Disponible en: http://www.slideshare. net/viacomunicacion/industria-farmac utica-expedientes-no-autorizados12845402

11. Laura Jimeno Muñoz. La Mafia Farmacéutica, el Negocio de la Enfermedad. Dyscovery Salud. Disponible en: http://www.youtube. com/watch?v=wIWuEAFlg1Y

Recibido: 15/04/14

Aprobado para su publicación: 18/05/14 